\title{
Variation of heart and lung radiation doses according to setup uncertainty in left breast cancer
}

\author{
Sunmin Park, Chai Hong Rim and Won Sup Yoon * (1)
}

\begin{abstract}
Purpose: Breast radiotherapy set-up is often uncertain. Actual dose distribution to normal tissues could be different from planned dose distribution. The objective of this study was to investigate such difference in dose distribution according to the extent of set-up error in breast radiotherapy.

Materials and methods: A total of $50 \mathrm{~Gy}$ with fraction size of $2 \mathrm{~Gy}$ was given to 30 left breasts with different set-ups applying a deep inspiration breath holding (DIBH) or a free breathing (FB) technique. Under the assumption that errors might come from translational axes of deep or caudal directions, the isocenter was shifted from the original tangential alignment every $2.5 \mathrm{~mm}$ to simulate uncertainty of deep and caudal tangential set-up in DIBH and FB. Changes were evaluated for dosimetric parameters for the heart, the left ventricle (LV), the left anterior descending coronary artery (LAD), and the ipsilateral lung.
\end{abstract}

Results: On the original plan, mean doses of heart and ipsilateral lung were 2.0 \pm 1.1 Gy and 3.7 \pm 1.4 Gy in DIBH and $8.4 \pm 1.3 \mathrm{~Gy}$ and $7.8 \pm 1.5 \mathrm{~Gy}$ in FB, respectively. The change of dose distribution for the heart in DIBH was milder than that in FB. The deeper the tangential set-up, the worse the heart, LV, LAD, and ipsilateral lung doses, showing as much as $49.4 \%, 56.4 \%, 90.3 \%$, and $26.1 \%$ shifts, respectively, in $5 \mathrm{~mm}$ DIBH setup. The caudal set-up did not show significant dose difference. In multiple comparison of DIBH, differences of mean dose occurred in all $7.5 \mathrm{~mm}$ deep set-ups for the heart $(p=0.025)$, the LV $(p=0.049)$, and LAD $(p=0.025)$ in DIBH.

Conclusions: To correct set-up error over indicated limitation for deep tangential set-up in DIBH at $5 \mathrm{~mm}$ action level, mean heart and ipsilateral lung doses are expected to increase approximately 50\% and $25 \%$, respectively.

Keywords: Breast cancer, Radiotherapy, Set-up uncertainty, Deep inspiration breath holding, Heart

\section{Introduction}

The issue of cardiac toxicity after breast radiotherapy was raised in the early 2000's. It has the following features. First, atherosclerotic change can cause coronary damage [1]. Second, cardiac events have continuously increased over a decade after radiotherapy. Therefore, long-term observation is needed [2, 3]. Third, pre-existing risk

*Correspondence: irionyws@korea.ac.kr

Department of Radiation Oncology, Ansan Hospital, Korea University, 123

Jeokgeum-ro, Danwon-gu, Ansan, Gyeonggi-do 15355, Republic of Korea factors such as smoking, old age, obesity, cardio-metabolic risk factors of hypertension and diabetes, and other cardiovascular or cerebrovascular disease can affect cardiac toxicity [4-6]. Most importantly, cardiac toxicity increases gradually per mean heart dose without a clear threshold [7]. Therefore, radiation dose for the heart should be avoided as low as reasonably achievable. The expert consensus has recommended deep inspiration breath hold (DIBH), prone position, and/or heart blocks to minimize heart dose [8]. The technique of DIBH is currently being applied to left breast cancer in many institutions. One study has compared DIBH and free breathing original author(s) and the source, provide a link to the Creative Commons licence, and indicate if changes were made. The images or other third party material in this article are included in the article's Creative Commons licence, unless indicated otherwise in a credit line to the material. If material is not included in the article's Creative Commons licence and your intended use is not permitted by statutory regulation or exceeds the permitted use, you will need to obtain permission directly from the copyright holder. To view a copy of this licence, visit http://creativecommons.org/licenses/by/4.0/. The Creative Commons Public Domain Dedication waiver (http://creativeco mmons.org/publicdomain/zero/1.0/) applies to the data made available in this article, unless otherwise stated in a credit line to the data. 
(FB) and found that DIBH can decrease $29.2 \%$ of mean heart dose and $43.5 \%$ of mean left anterior descending coronary artery (LAD) dose [9]. In a Asian cohort, the mean heart dose reduction throughout DIBH compared to $\mathrm{FB}$ is $47 \%$. This effect is more significant in those with low body mass index [10].

Tangential irradiation method is considered the most common and effective method in whole breast radiotherapy to minimize radiation dose to the opposite breast. In recent years, field-in-field techniques have been combined to further reduce ambient dose. However, because of uneven body surface, irregular breathing, incomplete body fixation, soft breast tissue, and so on, set-up uncertainty has become a limiting factor for distributing radiation dose as planned [11]. Then, with a deep set-up which is harmful to normal tissues such as the heart or the ipsilateral lung, to what extent is the radiation dose exceeded and what is the acceptable action level to correct set-up errors in clinical practice? No studies have addressed these questions. Thus, the objective of this study was to investigate dose distribution in the organs at risk (OARs) of heart, sub-segments of heart, and ipsilateral lungs according to set-up uncertainty, analyze characteristics, and assume the dose increase of OARs according to the action level of set-up error.

\section{Methods and materials}

\section{Patients}

Of patients receiving breast conserving surgery including sentinel lymph node biopsy with clinical T1-2N0 stage, those with left breast cancer who underwent adjuvant radiotherapy for whole breast alone were reviewed. Neoadjuvant chemotherapy was allowed and pathological N1 stage not to need additional axillary field was included. Each of 15 patients were identified in DIBH and FB. Because our institution has applied DIBH since October 2019, 15 patients consecutive from November 2019 to February 2020 were selected for the DIBH group. To minimize the effect of OARs by the different characteristics of body contour between DIBH and FB groups, FB group was selected based on clinical target volume (CTV) of breast [12]. Of 33 patients from October 2017 to May 2018, 15 patients for the FB group were paired with the DIBH group considering the approximate CTV. This retrospective study was approved by the Institutional Review Board of Ansan Hospital, Korea University, Republic of Korea.

For computed tomography (CT) simulation, a Brilliance Big Bore Oncology CT system (Philips Medical Systems, Nederland) and a Breastboard (Civco, Orange City, IA, USA) as immobilization devices were utilized. All set-ups were done at a supine position with an elevation of both arms above the head. CT contrast was administrated to enhance vascular structures and tumor bed. CT scans were sliced with a thickness of $3 \mathrm{~mm}$. While there was no education of breathing control for the FB group, the concept of DIBH was explained to patients on the first consultation day. Self-training was proceeded to hold their breath for a minimum of $20 \mathrm{~s}$ with a feeling of inhaling a small $1000 \mathrm{cc}$ plastic bottle for the DIBH group. Patients who had difficulty holding their breath for more than $20 \mathrm{~s}$ in the prior practice were excluded in DIBH. Our institution performed daily verification using the electronic portal images, Portal Vision aS1000 (Varian Medical System, Palo Alto, CA, USA) and checked the stability of chest wall during DIBH using the Real Time Position Management system (Varian Medical System).

\section{Radiotherapy planning}

Dose distribution was calculated with a radiation therapy planning system, a Varian Eclipse version 15.1 (Varian Medical System) using Anisotropic Analytical Algorithm. For CTV of the whole breast, ESTRO guideline was considered and $5 \mathrm{~mm}$ from the body surface of the CTV ( $4 \mathrm{~mm}$ for the small sized breast less than $400 \mathrm{cc}$ ) was edited [13]. To delineate OARs of the heart and sub-segments (left ventricle (LV) and LAD) of heart, the report of cardiac contouring atlas by Duane et al. [14] was used as a reference. The ipsilateral lung was delineated with CT window level and width of $0 / 1000 \mathrm{HU}$. The prescribed dose was modified as 50 Gy with 25 fractions to all patients to cover CTV $>95 \%$ with prescribed dose $>95 \%$ without maximum CTV dose $>107 \%$. The field-in-field technique using $6 \mathrm{MV}$ photon beams was made. For this study, delineation of the CTV and OARs and treatment plans were newly verified in consultation with two experienced radiation oncologists (Yoon and Rim).

\section{Study simulation}

For this study, we simulated two main conditions of setup error in a separate way: (1) in the deep direction (virtual perpendicular direction from the original tangential alignments); and (2) in the caudal direction of iso-center. Under the assumption that errors from rotational position and other directions were corrected, the isocenter shifted in deep and caudal directions every $2.5 \mathrm{~mm}$ until reaching $15 \mathrm{~mm}$ error (Fig. 1). After the isocenter was moved as much as each set-up error, dose distribution was recalculated. Thus, uncertainties of deep tangential and caudal set-up were simulated.

\section{Statistics}

Mean dose, V10Gy, and V20Gy of heart, mean dose and V20Gy of LV, mean dose and V30Gy of LAD, and mean dose, V10Gy, and V30Gy of ipsilateral lung were 


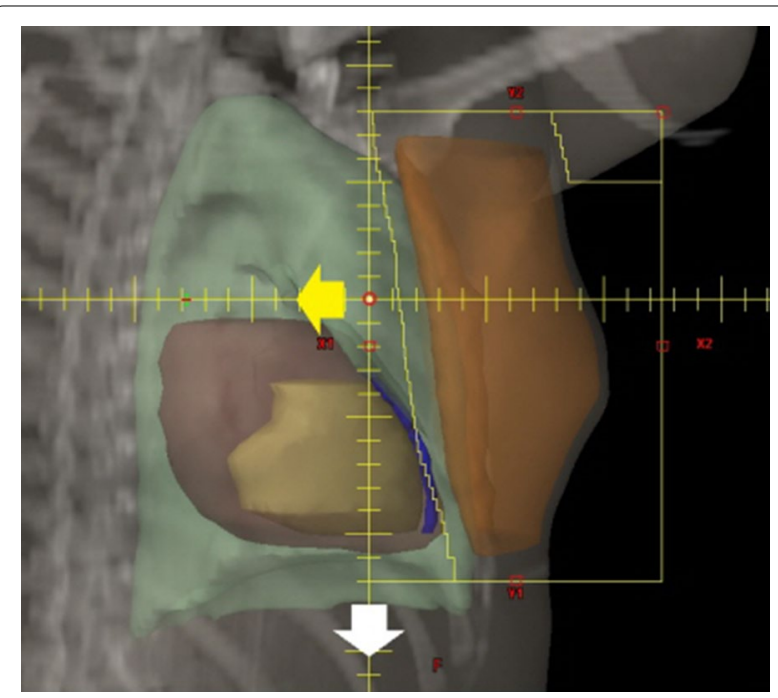

Fig. 1 Beam's eye view of medial tangential field. After the organ at risks and target volume were drawn (Heart; brown, Left ventricle; yellow, left anterior descending coronary artery; blue, Lung; green, breast target volume; Orange) and original tangential fields were aligned, translation movement of deep (yellow arrow) and caudal (white arrow) directions was simulated in every $2.5 \mathrm{~mm}$ and $5 \mathrm{~mm}$ interval till $15 \mathrm{~mm}$ set-up error, respectively measured. Each parameter was presented with a mean (M) \pm standard deviation (SD). The difference between FB and DIBH groups was examined with an independent two sample $T$ test. The difference in dose distribution between the original plan and each simulated set-up plan was calculated in both absolute dose (Gy) and the relative ratio on the basis of the original dose (\%). Then, it was compared with a paired T-test. In addition, multiple comparisons were performed with LSD (least significant difference) method to compare differences between simulated set-ups and to search the point as action level. A two-sided $p<0.05$ was considered significant. SPSS 20.0 (IBM SPSS Inc., Chicago, IL, USA) was used for all statistical analyses.

\section{Results}

\section{Patient characteristics}

After matching DIBH and FB groups according to CTV, 15 patients in each group were selected. Median age was 54 years (range, 41-66 years) for the DIBH group and 48 years (range, 39-63 years) for the FB group. For OARs, the ipsilateral lung (mean $923.1 \mathrm{ml}$ vs. $1600.7 \mathrm{ml}, p<0.001$ ) was larger in DIBH group. However, there was no volume difference of heart or its sub-segments (Table 1 ).

\section{Original plan of DIBH and FB}

On the original plan, mean doses of the heart were $2.0 \pm 1.1$ Gy (range, 0.85-4.95 Gy) and 3.7 \pm 1.4 Gy (range, 1.7-6.15 Gy) in DIBH and FB groups, respectively. Mean doses of $\mathrm{LV}$ and $\mathrm{LAD}$ were $3.3 \pm 2.5$ Gy and $17.8 \pm 12.7$ Gy in DIBH and $6.0 \pm 2.3$ Gy and $35.9 \pm 9.6$ Gy in FB, respectively. These results showed benefits of DIBH for decreasing doses for heart and its sub-segments in comparison with FB. Mean doses of the ipsilateral lung were $8.4 \pm 1.3$ Gy (range, 6.1-11.1 Gy) and $7.8 \pm 1.5$ Gy (range, 5.7-11.4 Gy) in DIBH and FB groups, respectively.

\section{Extent of dose difference}

The deeper the tangential set-up was, the worse the mean heart and ipsilateral lung dose became as much as 0.23 Gy and 0.44 Gy per $\mathrm{mm}$ to $10 \mathrm{~mm}$ shift in DIBH, and 0.37 Gy and 0.46 Gy in $\mathrm{FB}$, respectively (all $p<0.001$ ). However, caudal set-up did not affect dose distribution of OARs in DIBH or FB group (Table 2).

Differences between DIBH and FB $(\triangle \mathrm{FB}$ (Deep setup-Original plan)- $\triangle \mathrm{DIBH}$ (Deep set-up-Original plan)) of mean heart and LV doses were 0.73 Gy $(95 \%$ CI $0.42-1.04 \mathrm{~Gy}, p<0.001)$ and 1.27 Gy (95\% CI $0.65-$ $1.88 \mathrm{~Gy}, p<0.001)$ at $5 \mathrm{~mm}$ and 1.49 Gy (95\% CI $0.85-$ $2.12 \mathrm{~Gy}, p<0.001)$ and $2.31 \mathrm{~Gy}(95 \% \mathrm{CI} 1.06-3.57 \mathrm{~Gy}$, $p=0.001$ ) at $10 \mathrm{~mm}$ deeper set-up (Fig. 2a, b). These results suggested that DIBH showed a relatively favorable dose distribution than FB in the case of deeper setup uncertainty for the heart and the LV. Mean LAD dose with a deep set-up of $10 \mathrm{~mm}$ in DIBH was similar with the original plan of FB (Fig. 2c). Mean ipsilateral lung dose showed a qualitative increase of about 2 Gy per $5 \mathrm{~mm}$ deeper set-up regardless breath technique. It was $2.15 \pm 0.17$ Gy versus $2.29 \pm 0.25$ Gy at $5 \mathrm{~mm}$ deep setup and $4.40 \pm 0.35$ Gy versus $4.63 \pm 0.52$ Gy at $10 \mathrm{~mm}$ deep set-up. (Fig. 2d) Mean heart and LV doses of DIBH increased $49.4 \pm 14.5 \%$ and $56.4 \pm 24.2 \%$ at $5 \mathrm{~mm}$ deeper set-up and $119.6 \pm 38.9 \%$ and $143.6 \pm 68.5 \%$ at $10 \mathrm{~mm}$ deeper set-up, respectively (Fig. 3).

In multiple comparison of $\mathrm{DIBH}$, mean doses were significantly different in all $7.5 \mathrm{~mm}$ deep set-ups for the heart (mean difference: $1.56 \mathrm{~Gy}, p=0.025$ ), the LV (mean difference: $2.87 \mathrm{~Gy}, p=0.049$ ), and the LAD (mean difference: $13.58 \mathrm{~Gy}, p=0.025)$ in DIBH. The mean dose difference was more sensitive in FB with a $5 \mathrm{~mm}$ deep set-up for the heart (mean difference: $1.69 \mathrm{~Gy}, p=0.012$ ), the LV (mean difference: $3.01 \mathrm{~Gy}, p=0.004$ ), and the LAD (mean difference: $7.02 \mathrm{~Gy}, p=0.001$ ). For the mean ipsilateral lung dose, the difference was developed at $2.5 \mathrm{~mm}$ deep set-up in DIBH (mean difference: $1.05 \mathrm{~Gy}, p=0.037$ ) and at $5 \mathrm{~mm}$ deep set-up in FB (mean difference: $2.27 \mathrm{~Gy}$, 


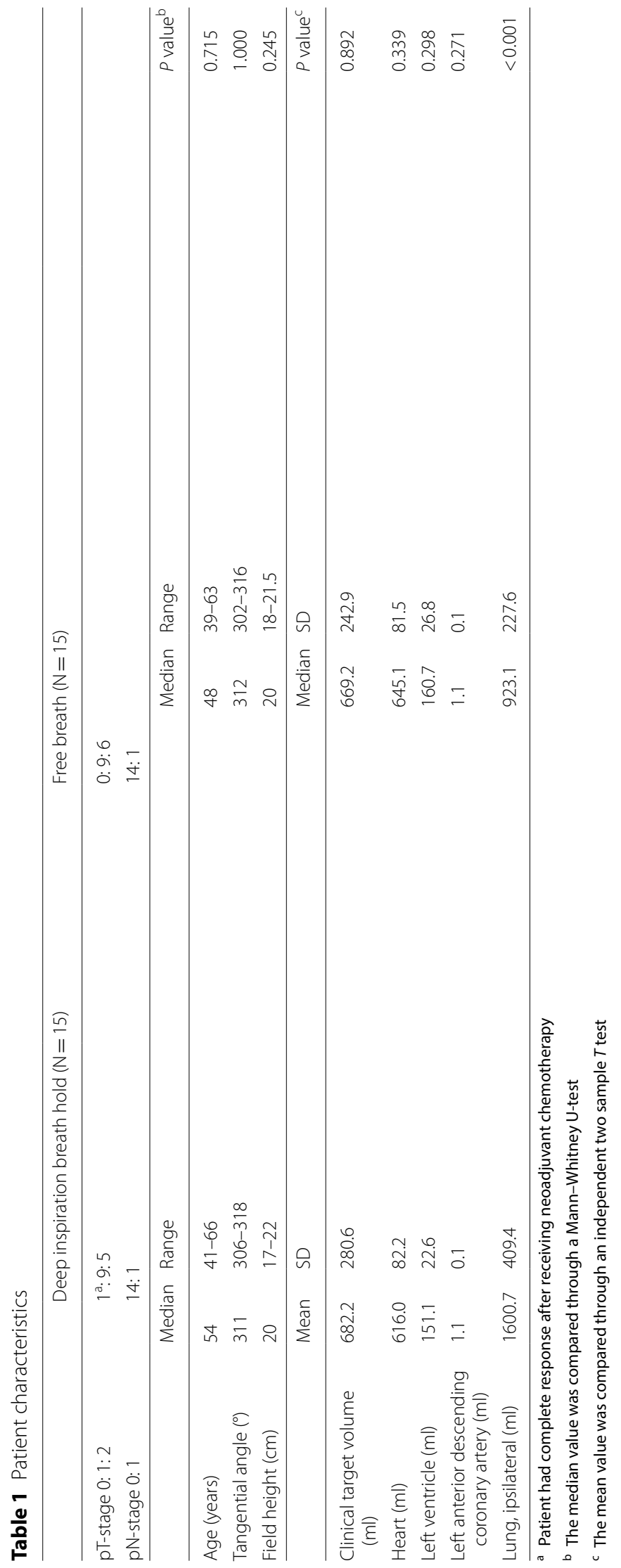


Table 2 Dose distribution for the organ at risks in terms of deep and caudal set-up errors in deep inspiration breath hold and free breath (Mean \pm (Standard deviation))

\begin{tabular}{|c|c|c|c|c|c|c|c|c|c|c|}
\hline & \multicolumn{3}{|l|}{ Heart } & \multicolumn{2}{|c|}{ Left ventricle } & \multicolumn{2}{|c|}{$\begin{array}{l}\text { Left anterior descending } \\
\text { coronary artery }\end{array}$} & \multicolumn{3}{|c|}{ Lung, ipsilateral } \\
\hline & Mean (Gy) & V10Gy (\%) & V20Gy (\%) & Mean (Gy) & V20Gy (\%) & Mean (Gy) & V30Gy (\%) & Mean (Gy) & V10Gy (\%) & V30Gy (\%) \\
\hline \multicolumn{11}{|c|}{ Deep inspiration breath hold $(N=15)$} \\
\hline No shift & $2.0(1.1)$ & $2.8(2.7)$ & $2.1(2.3)$ & $3.3(2.5)$ & $3.8(5.1)$ & $17.8(12.7)$ & $29.3(31.2)$ & $8.4(1.3)$ & $19.7(3.1)$ & $12.8(2.7)$ \\
\hline \multicolumn{11}{|l|}{ Deep } \\
\hline $2.5 \mathrm{~mm}$ & $2.5(1.4)$ & $3.8(3.2)$ & $2.9(2.8)$ & $4.1(2.9)$ & $5.4(6.3)$ & $22.2(13.2)$ & $38.7(31.8)$ & $9.4(1.3)$ & $22.1(3.2)$ & $15.0(2.9)$ \\
\hline $5 \mathrm{~mm}$ & $3.0(1.6)$ & $4.9(3.8)$ & $3.9(3.3)$ & $5.0(3.4)$ & $7.4(7.3)$ & $26.9(13.0)$ & $50.9(30.6)$ & $10.5(1.3)$ & $24.6(3.2)$ & $17.2(2.9)$ \\
\hline $7.5 \mathrm{~mm}$ & $3.6(1.8)$ & $6.3(4.3)$ & $5.1(3.8)$ & $6.2(3.9)$ & $9.9(8.4)$ & $31.4(12.9)$ & $61.7(29.3)$ & $11.6(1.4)$ & $27.1(3.3)$ & $19.6(2.9)$ \\
\hline $10 \mathrm{~mm}$ & $4.3(2.1)$ & $7.9(4.8)$ & $6.6(4.4)$ & $7.5(4.3)$ & $12.7(9.5)$ & $35.1(13.1)$ & $69.9(30.5)$ & $12.8(1.4)$ & $29.6(3.4)$ & $22.0(3.0)$ \\
\hline $12.5 \mathrm{~mm}$ & $5.0(2.3)$ & $9.7(5.3)$ & $8.2(4.90$ & $8.9(4.7)$ & $15.8(10.5)$ & $38.0(13.1)$ & $76.0(32.0)$ & $13.9(1.4)$ & $32.0(3.4)$ & $24.4(3.0)$ \\
\hline $15 \mathrm{~mm}$ & $5.9(2.5)$ & $11.7(5.8)$ & $10.0(5.4)$ & $10.5(5.1)$ & $19.3(4.3)$ & $40.7(12.1)$ & $81.0(30.4)$ & $15.0(1.5)$ & $34.5(3.5)$ & $26.9(3.1)$ \\
\hline \multicolumn{11}{|l|}{ Caudal } \\
\hline $5 \mathrm{~mm}$ & $2.1(1.2)$ & $3.0(2.8)$ & $2.3(2.4)$ & $3.5(2.6)$ & $4.1(5.4)$ & $18.7(13.0)$ & $32.3(30.8)$ & $8.6(1.2)$ & $20.3(2.9)$ & $13.4(2.6)$ \\
\hline $10 \mathrm{~mm}$ & $2.2(1.2)$ & $3.2(3.0)$ & $2.5(2.5)$ & $3.7(2.7)$ & $4.5(5.7)$ & $19.6(13.2)$ & $32.9(32.6)$ & $8.9(1.1)$ & $20.9(2.7)$ & $14.0(2.3)$ \\
\hline $15 \mathrm{~mm}$ & $2.3(1.3)$ & $3.5(3.2)$ & $2.7(2.7)$ & $3.9(2.9)$ & 4.9() $6.1)$ & $20.6(13.5)$ & $34.7(32.1)$ & $9.1(1.0)$ & $21.4(2.6)$ & $14.5(2.1)$ \\
\hline \multicolumn{11}{|c|}{ Free breath $(\mathrm{N}=15)$} \\
\hline No shift & $3.7(1.4)$ & $6.6(3.2)$ & $5.3(2.8)$ & $6.0(2.3)$ & $9.1(5.2)$ & $35.9(9.6)$ & $72.6(24.7)$ & $7.8(1.5)$ & $17.7(3.6)$ & $11.9(3.2)$ \\
\hline \multicolumn{11}{|l|}{ Deep } \\
\hline $2.5 \mathrm{~mm}$ & $4.5(1.5)$ & $8.4(3.5)$ & $7.0(3.2)$ & $7.4(2.5)$ & $12.2(5.7)$ & $40.2(6.8)$ & $83.8(15.5)$ & $8.9(1.5)$ & $20.2(3.7)$ & $14.2(3.3)$ \\
\hline $5 \mathrm{~mm}$ & $5.4(1.7)$ & $10.4(3.9)$ & $8.8(3.5)$ & $9.0(2.7)$ & $15.7(6.1)$ & $42.9(5.4)$ & $89.0(12.2)$ & $10.1(1.6)$ & $22.7(3.8)$ & $16.7(3.4)$ \\
\hline $7.5 \mathrm{~mm}$ & $6.4(1.8)$ & $12.7(4.2)$ & $10.9(3.9)$ & $10.7(2.8)$ & $19.5(6.5)$ & $44.7(4.3)$ & $92.0(10.0)$ & $11.2(1.6)$ & $25.2(3.8)$ & $19.1(3.5)$ \\
\hline $10 \mathrm{~mm}$ & 7.4 (1.9) & $15.1(4.5)$ & $13.2(4.2)$ & $12.4(2.9)$ & $23.5(6.9)$ & $46.1(3.5)$ & $94.5(7.8)$ & $12.4(1.7)$ & $27.8(3.9)$ & $21.6(3.5)$ \\
\hline $12.5 \mathrm{~mm}$ & $8.6(2.1)$ & $17.7(4.7)$ & $15.7(4.5)$ & $14.3(3.0)$ & $27.7(7.2)$ & $47.2(2.6)$ & $96.8(5.8)$ & $13.6(1.7)$ & $30.4(4.0)$ & $24.2(3.6)$ \\
\hline $15 \mathrm{~mm}$ & $9.8(2.2)$ & $20.5(5.0)$ & $18.3(4.7)$ & $16.3(3.1)$ & $32.1(7.4)$ & $48.0(1.8)$ & $98.2(3.9)$ & $14.8(1.8)$ & $33.0(4.0)$ & $26.7(3.7)$ \\
\hline \multicolumn{11}{|l|}{ Caudal } \\
\hline $5 \mathrm{~mm}$ & $3.8(1.5)$ & $6.9(3.4)$ & $5.6(3.0)$ & $6.2(2.5)$ & $9.6(5.5)$ & $36.2(10.0)$ & $74.2(24.3)$ & $7.9(1.4)$ & $17.9(3.5)$ & $12.2(3 . .1)$ \\
\hline $10 \mathrm{~mm}$ & $3.9(1.6)$ & $7.2(3.7)$ & $5.9(3.3)$ & $6.4(2.6)$ & $10.1(5.9)$ & 36.4 (10.6) & $74.2(25.6)$ & $8.0(1.4)$ & $18.1(3.4)$ & $12.5(3.0)$ \\
\hline $15 \mathrm{~mm}$ & $4.1(1.7)$ & $7.5(4.0)$ & $6.2(3.6)$ & $6.6(2.8)$ & $10.6(6.3)$ & $36.5(11.2)$ & $72.6(30.3)$ & $8.1(1.4)$ & $18.3(3.3)$ & $12.7(3.0)$ \\
\hline
\end{tabular}

The prescribed dose was 50 Gy with 25 fractions in all plans

$p<0.001$ ) (Table 3). If the practical action level to determine re-setup was given as $5 \mathrm{~mm}$ deep in DIBH, the maximum increases of V20 Gy for the heart, V20 Gy for the LV, V30 Gy for the LAD, and V30 Gy for ipsilateral lung were expected till $1.8 \pm 1.1 \%, 3.6 \pm 2.5 \%, 21.6 \pm 20.3 \%$, and $4.5 \pm 0.4 \%$, respectively.

\section{Discussion}

This study evaluated effects of set-up errors that might occur in daily practice of tangential breast irradiation on OARs. The concave part of the heart was included in the tangential radiation field first. As deep set-up error increases, dose change steeply increases in a certain range. On the other hand, since lungs are originally planned with the concave part already included in the tangential field, a quantitative dose increase occurs according to deep set-up error per mm. Based on our calculations, it seems possible that unexpected cardiac and pulmonary toxicity on original radiotherapy planning could be presented due to an inadvertent delivery without adjusting deep set-up error.

For heart and its sub-segments, DIBH was insensitive to deterioration of mean dose for the same set-up error compared to FB. It was more beneficial given that the original planned dose in DIBH was smaller than FB for those OARs. Based on a previous study showing that the relative risk of acute major coronary events is $7.4 \%$ per Gy [7], DIBH can reduce major coronary events by roughly $5 \%$ for the same $5 \mathrm{~mm}$ deep set-up compared to FB by reducing 0.7 Gy of mean heart dose. Although results with DIBH were evaluated to be somewhat worse for the ipsilateral lung than those with FB, the difference was manageable considering the threshold dose of pulmonary toxicity.

It is known that each radiotherapy facility in Korea accounts for $25 \%$ of the burden of breast radiotherapy 


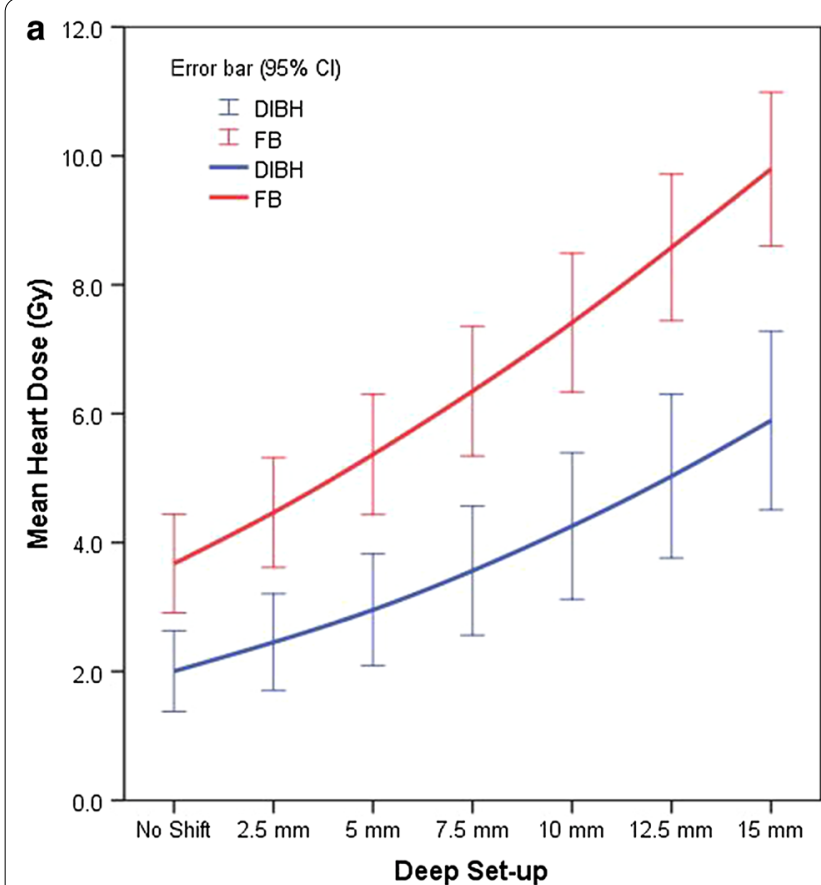

b
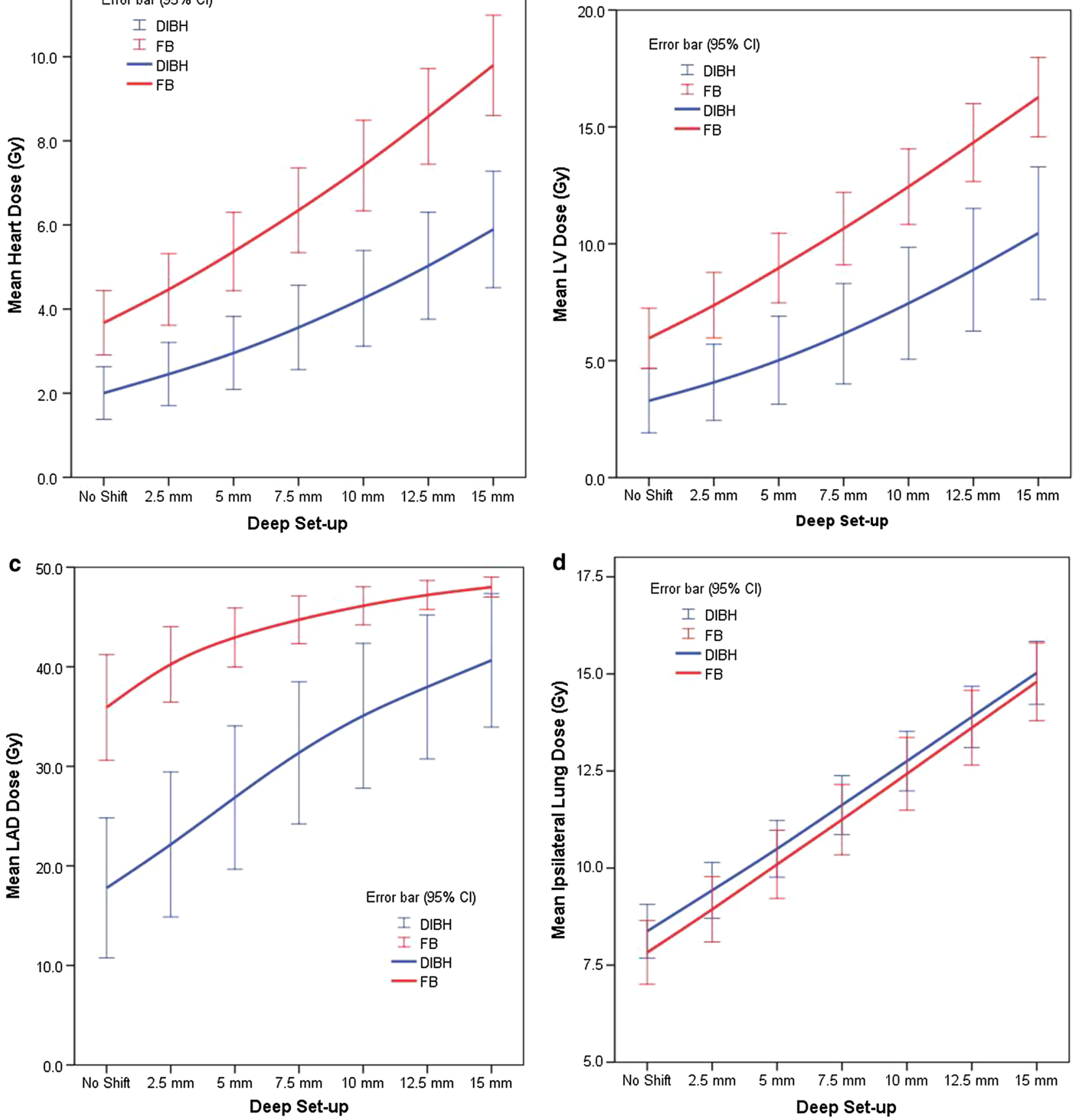

Fig. 2 The increase of mean dose distribution (Gy) from the original plan to worsen errors in deep set-up error. a Heart, $\mathbf{b}$ left ventricle, $\mathbf{c}$ left anterior descending coronary artery, and $\mathbf{d}$ ipsilateral lung

[15]. Of course, it would be ideal if all set-up errors can be corrected and the planned dose can be presented. However, there is a necessity about an action level as long as there are practical limitations. When we only examined statistical changes in mean value of heart dose for DIBH, not the risk of cardiac toxicity, the significant differences began to be shown from $7.5 \mathrm{~mm}$ deep setup. Therefore, we carefully assumed an action level of $5 \mathrm{~mm}$ deep in DIBH. The obvious one is that the degree of action level in FB needed to be strictly set. When this pattern of deep set-up error within $2.5 \mathrm{~mm}$ and $5 \mathrm{~mm}$ consistently developed in the entire radiotherapy period 


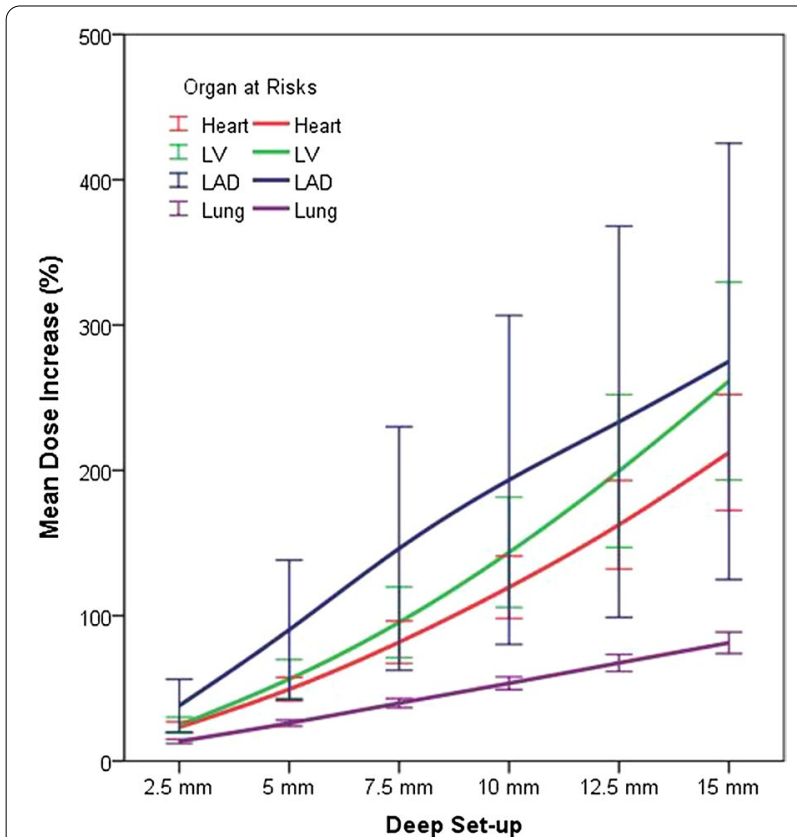

Fig. 3 The changes of mean dose distribution (\%) of worsen errors against the original plan in deep set-up error of deep inspiration breath hold

of FB, our study showed that approximately $23 \%$ and $49 \%$ of heart dose could increase, respectively, in comparison with the original plan. In modern series, median mean heart doses for left side breast cancer applying conventional (50 Gy in 25 fractions, DIBH 27.8\%) and hypofraction (42.6 Gy in 16 fractions, DIBH 14.6\%) schedule were 2.16 Gy and 1.47 Gy, respectively [16]. When our study results of DIBH are applied to the above study, cardiac dose can rise up to 3.23 Gy and 2.20 Gy under condition of $5 \mathrm{~mm}$ deep set-up error, respectively. Automated heart edge detection in cine MV image has been proposed [17]. If such technology is commercialized, adaptive radiotherapy could be applied to systematically monitor cardiac dose so that cardiac dose can be controlled below the constraint of each institution.

It is expected that set-up error can be controlled within about $4 \mathrm{~mm}$ by utilizing currently developed technology. In comparison with conventional laser-based set-up, surface guided radiotherapy using optical surface scanning system (OSS) can significantly reduce set-up errors, showing that $95 \%$ of fractions are within the clinical action level of $\leq 4 \mathrm{~mm}$ in any direction [18]. Patients with frequent set-up errors require more thorough management. Patients with uncertainty of initial treatment associated with inter-fractional variation should be carefully observed in the entire treatment period [19].

As DIBH requires holding the breath for more than $20 \mathrm{~s}$ and maintaining the same posture, reproducibility

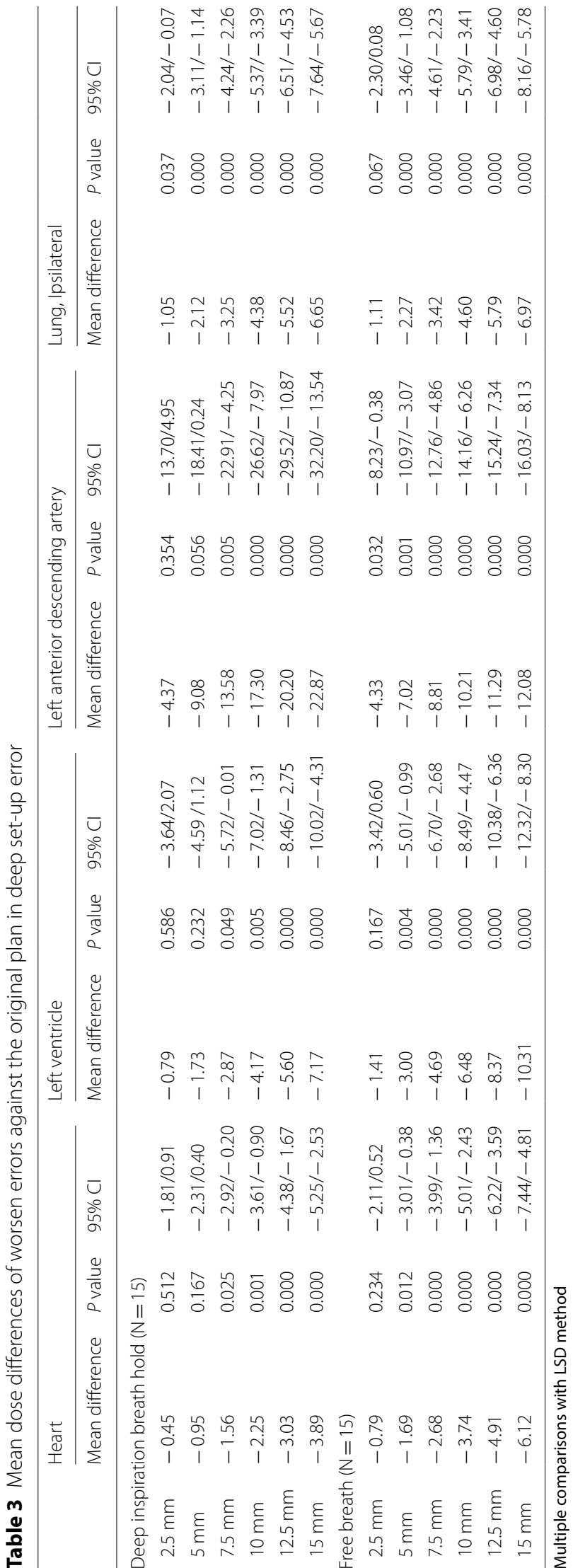


during radiotherapy is an important issue. A study estimating intra-fractional error using real time monitoring of OSS has presented that the mean motion during DIBH is small with $<1 \mathrm{~mm}$ translational and $1^{\circ}$ rotational deviation [20]. In another study, set-up error during DIBH was measured using continuous portal imaging in 58 patients. The standard deviation of intra-fractional motion was $0.5 \mathrm{~mm}$. However, large error exceeding $5 \mathrm{~mm}$ was occasionally presented in $12.1 \%$ of patients [21]. Cardiac motion affects cardiac dose. Distance variation from systolic to diastole was $\leq 4 \mathrm{~mm}$ for the $\mathrm{LV}$ and $\leq 3 \mathrm{~mm}$ for the heart and the LAD with a maximum dose of $5.2 \mathrm{~Gy}$ for the LV and a mean dose difference of 4.6 Gy for the LAD [22].

For lung cancer, lung dose constraint such as mean lung dose $<20 \mathrm{~Gy}, \mathrm{~V} 20 \mathrm{~Gy}<30 \%$, V $5 \mathrm{~Gy}<65 \%$, and absolute volume lung spared $>5 \mathrm{~Gy},<500 \mathrm{ml}$ was recommended to protect radiation induced lung injury [23]. In a systemic review of recent reports regarding lung dose of breast radiotherapy, the average mean ipsilateral lung dose was 8.4 Gy for whole breast radiotherapy without breathing adaptation [24]. Therefore, the occurrence of lung toxicity is modest. Symptomatic pulmonary events of grade 2 developed in $2.7 \%$ of whole breast radiotherapy in actual modern practice [25]. The increase of mean lung dose was significantly correlated with lower lung volume and larger treatment volume [26]. In our study, the mean ipsilateral lung dose increased approximately 1 Gy per $2.5 \mathrm{~mm}$ deeper set-up, reaching 10 Gy provided that the action level was $5 \mathrm{~mm}$ deep for the heart.

Although excluded from the evaluation of this study, the dose distribution of CTV would be essential as much as OARs. The sub-fields of field-in-field technique are manually reconstructed taking account of the dose clouds in each tangential field and the broad deviation of dose distribution for CTV could be developed according to characteristics of breast contour and physician's principle [27]. Therefore, the dose distribution of CTV related to the extent of caudal and deep set-up error could not show the uniform pattern on a case by case basis. For CTV or tumor bed, it is necessary that the set-up variation would be investigated in the different setting of tumor location (e.g. deep seated tumor, tumor on border of tangential field) and other direction of set-up error (e.g. shallow setup) in further study.

This study considered the coverage of CTV as the most important factor when making a radiation plan without modifying the plan according to the proximity of the heart. Due to such principle, the original plan dose was somewhat high, especially for LAD. The DEGRO expert panel recommends cardiac dose constraints as mean heart dose $<2.5$ Gy; mean LV dose $<3$ Gy; V5 Gy of $\mathrm{LV}<17 \%$; V23 Gy of $\mathrm{LV}<5 \%$; mean LAD dose $<10$ Gy;
V30 Gy of $\mathrm{LAD}<2 \%$; and V40 Gy of $\mathrm{LAD}<1 \%$ [28]]. In actual treatment, if a radiation field is tailored by weighting the location of tumor bed and heart toxicity, it will be possible to maintain a cardiac dose as low as reasonably achievable. In addition, since this study was not a comparative evaluation of the set-up of DIBH and FB in the same patient, there might be errors depending on body contour of the selected patient. Lastly, it is important to note that in actual treatment, uncertainty of set-up may complexly occur besides our deep and caudal set-up. However, the evaluation was performed on the premise of a deep and caudal set-up.

\section{Conclusions}

Relatively modest set-up errors can meaningfully increase doses to the lung and heart. Under a deep set-up error within $5 \mathrm{~mm}$, mean heart and ipsilateral lung doses increased up to $49.4 \%$ and $26.1 \%$ of original plan dose in $\mathrm{DIBH}$, respectively. Compared to FB, DIBH can reduce the relative cardiac dose for the same extent of set-up errors in left breast cancer. It is necessary to keep in mind that radiation with a higher dose than the planned dose in actual radiation treatment could be irradiated. Thus, it is important to establish an action level for a set-up error suitable for treatment circumference of each institution.

\section{Abbreviations \\ DIBH: Deep inspiration breath holding; FB: Free breathing; LV: Left ventricle; LAD: Left anterior descending coronary artery; CTV: Clinical target volume; CT: Computed tomography; OAR: Organs at risk; LSD: Least significant difference; OSS: Optical surface scanning system.}

\section{Acknowledgements}

Not applicable.

\section{Authors' contributions}

WSY designed the overall study with contributions from SP. SP and CHR collected and analyzed data. All authors read and approved the final manuscript.

\section{Funding}

This work was supported by Korea University (Grant Numbers K2010971).

\section{Availability of data and materials}

The data that support the findings of this study are available in Ansan Hospital, Korea University.

\section{Declarations}

Ethics approval and consent to participate Not applicable.

\section{Consent for publication}

Not applicable.

\section{Competing interests}

The authors declare no conflict of interest.

Received: 5 November 2020 Accepted: 11 April 2021

Published online: 20 April 2021 


\section{References}

1. Stewart FA, Seemann I, Hoving S, Russell NS. Understanding radiationinduced cardiovascular damage and strategies for intervention. Clin Oncol (R Coll Radiol). 2013;25(10):617-24.

2. Harris EE, Correa C, Hwang WT, Liao J, Litt HI, Ferrari VA, et al. Late cardiac mortality and morbidity in early-stage breast cancer patients after breastconservation treatment. J Clin Oncol. 2006:24(25):4100-6.

3. Weberpals J, Jansen L, Muller OJ, Brenner H. Long-term heart-specific mortality among 347476 breast cancer patients treated with radiotherapy or chemotherapy: a registry-based cohort study. Eur Heart J. 2018;39(43):3896-903.

4. Taylor C, Correa C, Duane FK, Aznar MC, Anderson SJ, Bergh J, et al. Estimating the risks of breast cancer radiotherapy: evidence from modern radiation doses to the lungs and heart and from previous randomized trials. J Clin Oncol. 2017;35(15):1641-9

5. Chang JS, Ko BK, Bae JW, Yu JH, Park MH, Jung Y, et al. Radiation-related heart disease after breast cancer radiation therapy in Korean women. Breast Cancer Res Treat. 2017:166(1):249-57.

6. Sung SY, Lee JH, Yang KH, Seo Y, Kang MY. Coronary event analysis in breast cancer patients who received breast-conserving surgery and postoperative radiotherapy: a Korean nationwide cohort study. J Breast Cancer. 2020;23(3):291-302

7. Darby SC, Ewertz M, McGale P, Bennet AM, Blom-Goldman U, Bronnum D, et al. Risk of ischemic heart disease in women after radiotherapy for breast cancer. N Engl J Med. 2013;368(11):987-98.

8. Smith BD, Bellon JR, Blitzblau R, Freedman G, Haffty B, Hahn C, et al. Radiation therapy for the whole breast: executive summary of an American Society for Radiation Oncology (ASTRO) evidence-based guideline. Pract Radiat Oncol. 2018;8(3):145-52.

9. Yeung R, Conroy L, Long K, Walrath D, Li H, Smith W, et al. Cardiac dose reduction with deep inspiration breath hold for left-sided breast cancer radiotherapy patients with and without regional nodal irradiation. Radiat Oncol. 2015:10:200.

10. Yamauchi R, Mizuno N, Itazawa T, Saitoh H, Kawamori J. Dosimetric evaluation of deep inspiration breath hold for left-sided breast cancer: analysis of patient-specific parameters related to heart dose reduction. J Radiat Res. 2020;61(3):447-56

11. Yoon WS, Das SK, Marks LB. The impact of set-up uncertainty on doseresponse estimates. Int J Radiat Oncol Biol Phys. 2019;105(3):477-8.

12. Ratosa I, Jenko A, Sljivic Z, Pirnat M, Oblak I. Breast size and dose to cardiac substructures in adjuvant three-dimensional conformal radiotherapy compared to tangential intensity modulated radiotherapy. Radiol Oncol. 2020;54(4):470-9.

13. Offersen BV, Boersma $\sqcup$, Kirkove C, Hol S, Aznar MC, Biete Sola A, et al. ESTRO consensus guideline on target volume delineation for elective radiation therapy of early stage breast cancer. Radiother Oncol. 2015;114(1):3-10.

14. Duane F, Aznar MC, Bartlett F, Cutter DJ, Darby SC, Jagsi R, et al. A cardiac contouring atlas for radiotherapy. Radiother Oncol. 2017;122(3):416-22.

15. Seo YS, Kim MS, Kang JK, Jang WI, Kim HJ, Cho CK, et al. The clinical utilization of radiation therapy in Korea between 2011 and 2015. Cancer Res Treat. 2018:50(2):345-55.
16. RazviY McKenzie E Wronski M, Zhang L, Vesprini D, Bosnic S, et al. Factors affecting mean heart dose in patients receiving breast radiotherapy from 2011 to 2018 in a single institution. J Med Imaging Radiat Sci. 2020;51:379-93.

17. Poulsen PR, Thomsen MS, Hansen R, Worm E, Spejlborg H, Offersen B. Fully automated detection of heart irradiation in cine MV images acquired during breast cancer radiotherapy. Radiother Oncol. 2019;152:189-95.

18. Kugele M, Mannerberg A, Norring Bekke S, Alkner S, Berg L, Mahmood F, et al. Surface guided radiotherapy (SGRT) improves breast cancer patient setup accuracy. J Appl Clin Med Phys. 2019;20(9):61-8.

19. Yang DS, Yoon WS, Chung SY, Lee JA, Lee S, Park YJ, et al. Set-up uncertainty during breast radiotherapy. Image-guided radiotherapy for patients with initial extensive variation. Strahlenther Onkol. 2013;189(4):315-20.

20. Tang X, Cullip T, Dooley J, Zagar T, Jones E, Chang S, et al. Dosimetric effect due to the motion during deep inspiration breath hold for left-sided breast cancer radiotherapy. J Appl Clin Med Phys. 2015;16(4):91-9.

21. Lutz CM, Poulsen PR, Fledelius W, Offersen BV, Thomsen MS. Setup error and motion during deep inspiration breath-hold breast radiotherapy measured with continuous portal imaging. Acta Oncol. 2016;55(2):193-200.

22. Bahig H, de Guise J, Vu T, Blais D, Chartrand-Lefebvre C, Nguyen NT, et al. In a heartbeat: an assessment of dynamic dose variation to cardiac structures using dual source computed tomography. Int J Radiat Oncol Biol Phys. 2018;102(4):950-9.

23. Hanania AN, Mainwaring W, Ghebre YT, Hanania NA, Ludwig M. Radiation-induced lung injury: assessment and management. Chest. 2019;156(1):150-62.

24. Aznar MC, Duane FK, Darby SC, Wang Z, Taylor CW. Exposure of the lungs in breast cancer radiotherapy: a systematic review of lung doses published 2010-2015. Radiother Oncol. 2018;126(1):148-54.

25. Wen G, Tan YT, Lan XW, He ZC, Huang JH, Shi JT, et al. New clinical features and dosimetric predictor identification for symptomatic radiation pneumonitis after tangential irradiation in breast cancer patients. J Cancer. 2017:8(18):3795-802.

26. McKenzie E, Razvi Y, Wronski M, Zhang L, Bosnic S, Vesprini D, et al. Trends and correlates of mean lung dose in patients receiving breast radiotherapy in a single institution from 2014 to 2018. Clin Oncol (R Coll Radiol). 2020;32:647-55

27. Ahmad I, Chufal KS, Bhatt CP, Miller AA, Bajpai R, Chhabra A, et al. Plan quality assessment of modern radiotherapy delivery techniques in left-sided breast cancer: an analysis stratified by target delineation guidelines. BJR Open. 2020;2(1):20200007

28. Piroth MD, Baumann R, Budach W, Dunst J, Feyer P, Fietkau R, et al. Heart toxicity from breast cancer radiotherapy: current findings, assessment, and prevention. Strahlenther Onkol. 2019:195(1):1-12.

\section{Publisher's Note}

Springer Nature remains neutral with regard to jurisdictional claims in published maps and institutional affiliations.

Ready to submit your research? Choose BMC and benefit from

- fast, convenient online submission

- thorough peer review by experienced researchers in your field

- rapid publication on acceptance

- support for research data, including large and complex data types

- gold Open Access which fosters wider collaboration and increased citations

- maximum visibility for your research: over 100M website views per year

At BMC, research is always in progress.

Learn more biomedcentral.com/submissions 